\title{
Conservation Choices in the Face of Sea-Level Rise: A Case Study on Marsh Migration from Phippsburg, Maine
}

\author{
Sahan T. M. Dissanayake and Meagan K. Hennessey
}

\begin{abstract}
We analyze the benefits of incorporating climate change into land conservation decisions using wetland migration under rising sea-levels as a case study. We use a simple and inexpensive decision method, a knapsack algorithm implemented in Excel, with (1) simulation data to show that ignoring sea-level rise predictions lead to suboptimal outcomes, and (2) an application to land conservation in Phippsburg, Maine to show the real-world applicability. The simulation shows an 11-percent to almost 30-percent gain in increased benefits when accounting for sea-level rise. The results highlight that it is possible to, and important to, incorporate sea-level rise into conservation planning.
\end{abstract}

Key Words: climate change, coastal conservation, sea-level rise, site-selection, reserve design

Land conservation organizations differ in their priorities, but all are focused on selecting land to preserve for the future. This would be challenging with complete information about land availability, conservation value, and costs, because difficult choices would have to be made regarding which piece of land is more important than another, leaving land not chosen open to development and degradation. The land selection problem is additionally complicated because conservation organizations are often faced with not only this type of informed tradeoff but also a lack of complete information. Imperfect information is especially prevalent in the face of climate change, the effects of which are already being seen and are virtually certain to continue and worsen in the coming decades (IPCC 2013). In this paper we

Sahan T. M. Dissanayake is an assistant professor of economics at Colby College and at Portland State University, and a Fellow of the Institute for Sustainable Solutions at Portland State and the Goldfarb Center for Public Affairs at Colby College. Megan Hennessey was an undergraduate student at Colby College (class of 2014) and currently works for the Park System for the State of Maine. Correspondence: Sahan T. M. Dissanayake - Department of Economics, Colby College, Diamond, 3rd floor 5230 Mayflower Hill Waterville, Maine 04901-8852-217.419.0452 " Email: sdissan2@gmail.com

The authors express their gratitude to two anonymous referees, the editor for this special issue, participants at the 2016 NAREA Workshop for feedback and comments on earlier drafts, and Juanita Wilson-Hennessey for data and information on the Marsh migration project. This research was partially supported by Colby College Student/Faculty Research Funds.

The views expressed are the authors' and do not necessarily represent the policies or views of any sponsoring agencies.

Agricultural and Resource Economics Review 46/2 (August 2017) 388-419

(C) The Author(s) 2017. This is an Open Access article, distributed under the terms of the Creative

Commons Attribution licence (http://creativecommons.org/licenses/by/4.0/), which permits unrestricted re-use, distribution, and reproduction in any medium, provided the original work is 
study one aspect of the uncertainty faced by conservation organizations, the impact of rising sea-levels.

The Arctic ice sheet is melting, storms are increasing in intensity, and dangerous heat waves are increasing in frequency (Holdren 2010). Some coastal roads will become impassable during storm surges, creating a dangerous emergency response scenario (MMM 2013), property values will be affected (Yohe et al. 1996), and land cover will change (Ando and Mallory 2012). These and other potential effects add an element of both risk and uncertainty to conservation decisions, with the potential for sea-level rise being especially problematic for conservation organizations focused on coastal conservation.

At the same time, in the past few years there have been multiple attempts to leave climate-change-based decision making out of the policy process. Perhaps the most widely known examples come from North Carolina, where the State Legislature passed a bill limiting the Coastal Resources Commission to the use of linear historical data and restricted use of scenarios with accelerated rates of sea-level rise (Krakauer 2012, Lee 2012). More recent efforts by the current Federal government to reduce funding for climate change and direct research away from climate change furthers this trend of decoupling climatechange-based predictions from the policy process.

This study aims to answer two questions: First, using simulated data and the knapsack optimization method, we show that there are expected benefits from anticipating sea-level rise, and that these benefits are sensitive to changes in budget, risk level, and range of uncertainty. We also show that ignoring likely sea-level rise due to climate change in policy planning can lead to suboptimal outcomes. Second, we look at what an accessible and useful method to incorporate uncertainty over sea-level rise is when deciding which land parcels to conserve. We use a case study with real data on marsh migration from Phippsburg, Maine to develop a decision-making approach that uses readily available software. This method is an inexpensive and relatively simple way to guide decision-makers' choices. We start the paper with an extensive literature review discussing land conservation under climate change and the current literature related to coastal conservation and sealevel rise.

\section{Motivation and Literature Review}

\section{What Does a Conservation Organization Need to Do?}

A conservation organization looking toward the future needs to know three basic things: land suitability, land availability, and a land selection strategy. Land suitability must be valued depending on the group's goals, i.e., a group concerned about marsh habitat will be interested in different pieces of land than a group concerned about a specific species that does not use marshes. 
Climate change directly influences land suitability by altering the habitat through its impacts; for example, in the case of sea-level rise, land may become submerged.

Land availability is simply whether or not the organization can own and use (in a way that is meaningful to them) the land. This is a question of both whether the land is for sale (either outright or via a land trust or similar arrangement) or not, and whether or not the land will be suitable for an acceptable period of time. The land selection process must identify those properties that are suitable and available, and then create a method to determine which ones are actually purchased based on their budget. We focus on this aspect in this study; specifically we discuss site selection methods (also called reserve design or systematic conservation methods) and then discuss the importance of accounting for the uncertainty from climate change.

\section{Land Conservation Methods}

Optimal site selection methods or systematic conservation methods focus on identifying optimal conservation areas given ecological criteria and conservation resource constraints (Haight and Snyder 2009, Moilanen and Ball 2009). The fundamental models, the set covering and maximal covering formulations introduced by Toregas and ReVelle (1973) and Church and ReVelle (1974), focused purely on the conservation outcomes; Kirkpatrick (1983), Underhill (1994), Camm et al. (1996), Possingham, Ball, and Andelman (2000), Rodrigues and Gaston (2002), and Önal (2004) present some of the early examples. Subsequently, multiple studies have shown that there are conservation gains from taking more economically minded approaches to designing reserves and land selection (Ando et al. 1998, Naidoo et al. 2006, Nelson et al. 2009, Strange et al. 2007). More recent studies extended the basic formulations to incorporate various spatial criteria in site selection such as boundary length minimization, clustering, connectedness, compactness, and contiguity (e.g. Williams and ReVelle 1996, 1998, Cova and Church 2000, Williams 2002, Fischer and Church 2003, Önal, and Briers 2003, 2006, Cerdeira, Gaston, and Pinto 2005, Önal and Wang 2008, Dissanayake, Önal, and Westervelt 2011, Dissnayake et al. 2012, Onal et al. 2016; see Williams, Revelle, and Levin 2005 and Boyd et al. 2015 for an extensive review).

Much of this work assumed a static framework and did not incorporate dynamic aspects such as changing land prices and availability, change in species distributions and land suitability and these dynamic aspects can impact the efficiency of outcomes (Costello and Polasky 2004, Armsworth et al. 2006). Some recent work has tackled the dynamic land conservation using stochastic dynamic programming (Costello and Polasky 2004, Strange et al. 2006, Sabbadin, Spring, and Rabier 2007) and integer programming (Snyder, Robert, and ReVelle 2005, Dissanayake and Onal 2011), constrained 
Markov decision processes (Newburn, Berck, and Merenlender 2006), metapopulation modeling (Moilanen 2002). At the same time, these methods do not explicitly model the uncertainty and risk due to climate change.

To deal with the uncertainty of climate change in the land conservation setting, scientists have suggested increasing the number of reserves and the connectivity between them (Ando and Hannah 2011). Decision makers may also choose to include the possibility of swapping or buying and selling parcels over time rather than being cemented in the choice they make today. Inclusion of the swapping decision has been shown to increase benefits (Strange, Jellesmark Thorsen, and Bladt 2006) but may not be realistic for all organizations, as many land trusts are set up in perpetuity.

Over the last few years, environmental economists working on conservation have also turned to modern portfolio theory, which is concerned with "how to allocate wealth among alternative assets" to model the conservation under uncertainty (Elton and Gruber 1997, 1743). Ando and Mallory (2012) illustrate how to use modern portfolio theory to handle conservation under the threat of climate change using the case study of conservation in the United States Prairie Pothole Region. According to their results, this uncertainty could be greatly reduced for a small sacrifice in expected returns, when the expected returns are high, highlighting that maximizing returns is not always the best approach when faced with uncertainty. Shah and Ando (2015) extend this framework to account for downside risk using a case study on bird conservation in the Eastern U.S. In summary, there are growing numbers of studies either using purely mathematical models, simulation studies, or actual data with complex models to identify optimal conservation areas.

Unfortunately, as Prendergast et al. (1999) point out, conservation theorists and practical conservationists are working in different worlds. Very few of the theoretical models being developed in the literature are actually being used in real life, with Australia (whose conservation agencies are developing their own techniques) and California being possible exceptions. There are varieties of reasons for this, from the inability of the algorithms being used to incorporate factors such as translocation and restoration considerations, the sporadic nature of land availability, ownership issues, or impact of climate change (Prendergast, Quinn, and Lawton 1999). While these are all issues theoretical models may be able to overcome in the future, another issue may still prevent even the best algorithms from being implemented. In many cases, conservation agents are faced with a difficult judgment call, whether they should spend money on data collection and modeling or on land purchasing. This may be confounded by a lack of knowledge or understanding on the part of the decision maker about the value of systematic conservation models, or the decision maker may simply not have access to the hardware or software necessary to run the algorithms, even where data are available Prendergast, Quinn, and Lawton 1999). 


\section{Climate Change and Sea Level Rise}

By the end of this century, 95 percent of ocean area is expected to be at a higher level than it is today, with approximately 70 percent of global coastlines within 20 percent of the global mean rise (IPCC 2013). This means almost no one can expect to gain land from changes in sea level, even if the level of loss is uncertain. However, local variations are expected (Jones 2013), a factor that must be kept in mind by local decision makers.

Nicholls, Hoozemans, and Marchand (1999) suggested that relative to a scenario without sea-level rise, the numbers of people who will be flooded during storm surges in an average year will be five times higher by the 2080s. In the short term, both lives and material wealth can be protected by moving away from the coast and avoiding areas below current sea-level, and through actions such as building levees. Acting now to limit greenhouse gas emissions may not be enough to prevent the necessity of these changes but would benefit future generations by limiting the level of sea-level rise seen during their lifetimes.

Though there is wide acceptance of climate change, there is uncertainty with regard to the outcomes, especially with regard to rising sea levels (IPCC 2013). Part of the uncertainty in sea-level rise predictions arises from the number of factors that influence sea-level rise. According to the IPCC (IPCC 2013), glacier mass loss and ocean thermal expansion from warming explain 75 percent of the observed global mean sea level rise since the early 1970s, but the future rate of glacier melt is itself uncertain. Changes in water temperatures and salinity will change currents, which may change water levels as well as affect storm systems, again changing the effects felt from sea-level rise (IPCC 2013).

Despite the potential benefits of adaptation steps taken today, it seems as though many individuals are only slowly taking these steps, if at all. The uncertainty inherent in the modeling of sea-level rise and the variability in effects may be part of why agents are not incorporating predictions into their decision-making. Global changes do not give much of an idea how much sea levels will rise in local areas, and the large range of predictions being published is likely to confuse the lay person. As climate change involves "highly unknown and to some extent, inherently random, long-term behavior" (Lontzek and Narita 2011), uncertainty and risk become a key component in understanding and formulating responses to rising sea levels. In this study we focus on land conservation, specifically coastal land conservation, and how sea level rise will impact coastal conservation decisions.

We first present a straightforward simulation example to highlight that incorporating climate-change-based sea-level predictions is important and that ignoring the predictions can lead to suboptimal outcomes for conservation organizations. We then follow with a case study from Phippsburg, Maine to highlight how the methods can be applied to guide conservation decision making. 
In general, for all conservation site selection applications, organizations must decide how to calculate benefits, depending on what the organization's goals are. A conservation group could consider habitat type or expected species conserved (Polasky et al. 2000), focus on protecting endangered species (Arthur et al. 2004), or find an optimal protection level above which gains come from an excessive cost (Strange et al. 2007). Depending on risk aversion, the organization may want to maximize the expected benefits, or they may want to aim for the highest likely benefit. These decisions are specific to individual groups and will be strongly influenced by the stakeholders. For example, a progressive private conservation group is expected to make different decisions than a government agency held accountable by a public holding the full spectrum of opinions on conservation. For the purposes of simulation work and the case study presented in this paper, we assume that benefits are directly correlated to the size of the protected land and therefore maximize the amount of conserved land as the objective function.

\section{Simulated Data: The Knapsack Problem}

We simulate the decision-making context of two different conservation organizations, one that incorporates predictions of sea-level rise into their decision-making process and one that does not. The simulation demonstrates that expectations of sea-level rise can be effectively incorporated into existing optimization methods and that failure to do so results in suboptimal outcomes. This then motivates the application to Marsh Migration presented in Section 4.

\section{Problem Description}

In order to compare the future benefits realized by two different conservation organizations using different selection methods (one that anticipates sea-level rise, the other does not), we use a basic optimization method, the knapsack algorithm, to compare the realized benefit of acquired land, given predicted sea-level rise and the cost of the land. While values of benefits, land costs, and predicted sea-level rise were randomly generated for simulation purposes, the proposed method can be directly applied to real data.

For this simulation and the application (next section), we use the size of the protected wetland area as the benefit or value from conservation. This is a proxy for the ecosystem value of the conserved land and is a simplification, as it ignores multiple benefits that can result from wetlands or the spatial arrangement of wetlands. At the same time, we use the simplest possible approach here to illustrate the conceptual model. If an organization wanted to focus on specific wetland types or locations or ecosystem-based benefits, the decision-making framework can easily be adopted to do so by replacing the size of the land by the desired benefits. 


\section{Simulation}

We simulate the knapsack method using 50 properties. For each property, land cost and land value were randomly generated using a uniform distribution between 0 and 10 . The size or area of the property in the "current" period was generated to be between 1 and 100, and the per-unit value of the property was calculated based on the size and land value. The predicted sealevel rise was between 0 and 100, meaning anywhere between zero to more than complete inundation for any given property could occur. The predicted land value at $\mathrm{N}$ years was determined by taking the area of each property remaining after $\mathrm{N}$ periods and multiplying by the per-unit value for that property. It is important to note that the definition of value will be specific to the needs of the conservation organization, but for this simulation may be thought of as an ordinal index of usefulness, meaning the higher the number the more advantageous the land. See Table 1 for a complete description of variables used.

For each comparison of expected outcomes for these two conservation organizations, their choices were determined using the following model:

$$
\begin{aligned}
\text { ExpectedBenefits }_{N}= & \sum \text { PropertyValue }_{N} * \text { PurchaseDecision } \\
& \text { s.t. } \sum \text { PropertyCost }_{1} * \text { Purchase Decision }_{1} \leq \text { Budget }_{1}
\end{aligned}
$$

Because one group (Group 1) incorporated expected sea-level rise in the decision-making process, their purchasing decision was based on the expected value for each property after $\mathrm{N}$ periods. The other organization (Group 2) did not incorporate expected sea-level rise in the decision-making process, instead choosing to purchase land based on the value in the current time period.

Table 1. Variables Used in the Random Knapsack Problem. All Values Were Randomly Generated.

\begin{tabular}{lll}
\hline Variable & \multicolumn{1}{c}{ Time } & \multicolumn{1}{c}{ Value } \\
\hline Land Cost & Present & Uniform (0 to 10) \\
Land Value & Present & Uniform (0 to 10) \\
Area & Present & Uniform (1 to 10) \\
Per Unit Land Value & Present & Land Value / Area \\
Predicted Sea Level Rise & N years in the future & Uniform (0\% to 100\%) \\
Predicted Area Remaining & N years in the future & $\begin{array}{c}\text { min A Area - Predicted } \\
\text { Sea Level Rise, 0 }\end{array}$ \\
Predicted Land Value & N years in the future & $\begin{array}{c}\text { Predicted Area Remaining * Per Unit } \\
\text { Land Value }\end{array}$ \\
& &
\end{tabular}


Table 2. Parameter Values for Each Scenario.

\begin{tabular}{lllll}
\hline & Scenario 1 & Scenario 2 & Scenario 3 & Scenario 4 \\
\hline $\begin{array}{l}\text { Budget } \\
\begin{array}{c}\text { Mean Variation } \\
\text { in Sea-Level Rise }\end{array}\end{array}$ & $\$ 150$ & $\$ 25-\$ 230$ & $\$ 150$ & $\$ 150$ \\
$\begin{array}{c}\text { Range of Variation } \\
\text { in Sea-Level Rise }\end{array}$ & $0 \%-100 \%$ & $0 \%-100 \%$ & $20 \%$ & $50 \%$ \\
\hline
\end{tabular}

We examine four separate scenarios, as presented in Table 2. The first scenario compares the difference in realized benefits and costs in each of 30 different simulations, in which the values were randomly generated according to Table 2 for each simulation. For the second scenario, the budgets were varied over a range of $\$ 25$ to $\$ 230$, all with a sea-level severity between 0 percent and 100 percent. The third scenario compares variations in the mean expected level of severity. The lowest mean was 10 percent, and the highest mean was 90 percent, all with a range of 20 percent and a budget of $\$ 150$. Fourth, a range of predicted sea-level rise from 10 percent to 50 percent, with mean severity of 50 percent and a budget of $\$ 150$ was used to explore increasing uncertainty. In all scenarios we compare the total benefits obtained by the myopic agent that ignores sea-level rise and the forward-looking agent that accounts for sea-level rise and the difference between the two outcomes.

The analysis we conduct does not account for the uncertainty of land type change as the value per unit of land remains constant through time. The value of the land may be calculated a number of ways in reality, but here we take it as a given. Finally, we assume a linear landscape that is one unit wide and given that we are considering the size of plots of land as our objective we do not incorporate discounting, rather we compare the available land $\mathrm{N}$ periods in the future. ${ }^{1}$ Despite these limitations, the exercise clearly and simply demonstrates the importance of incorporating expectations of sea-level rise while building a decision framework to analyze optimal coastal land conservation.

\footnotetext{
1 The climate change variable that affects our model/results is sea-level rise. The level of sealevel rise at a given time period depends on multiple factors including temperature, accumulated GHGs, and also the time period, and this would be too complicated for us to model for the purposes of this study, which is to understand optimal coastal conserve decision making. Therefore, as constructed, our model works with sea level and is agnostic to the actual time period when a specific sea level arises. For example, sea level rise of 3 feet may occur in 50 years, or in 100 years, and what we model is how accounting for the sea-level rise affects efficiency of selections vs. not accounting for sea level. The benefits we measure are the realized benefits in the future. Therefore, $\mathrm{N}$ is arbitrary (or more accurately is a function of sealevel rise). Given this, there is no explicit discounting in the model, as N varies with exogenous variables, and we focus on the realized value.
} 


\section{Comparing Models in Fixed Scenarios}

As expected, incorporating the predictions of sea-level rise into the decisionmaking process resulted in higher realized benefits at a lower cost, on average. Realized benefits when incorporating expectations of sea-level rise were greater than realized benefits when ignoring expectations of sea-level rise in every scenario. With the range in total realized benefits between a maximum of 97 and minimum of 23 between each model, the average difference was 7 (SD 3.79) land units over the thirty scenarios (maximum difference was 15 , minimum difference was 1 ). A one-tail mean sample comparison test indicates the benefits of incorporating sea-level rise are statistical significant at the 10-percent level ( $p$-value $=0.061$ ). This translates to an approximately 11-percent increase in benefits compared to a myopic decision maker that ignores sea-level rise.

The total cost when incorporating expectations of sea-level rise were less than or equal to the total costs when ignoring expectations of sea-level rise in 29 of the 30 simulations. With a maximum cost of 150 (the set budget), and a minimum cost of 90 between the two models, the average difference (calculated as the cost for the model incorporating expectations minus the cost for the model ignoring them) was 26 (SD 17.33) over the 30 scenarios (the maximum difference was 60 and the minimum difference was -8). A one tail, mean sample comparison test indicates savings from incorporating sealevel rise are statistically significant statistical significant at any reasonable level ( $p$-value $<0.0000$ ). This translates to an approximately 20 -percent decrease in costs compared to a myopic decision maker that ignores sea-level rise.

We then conduct robustness tests of these results by varying the budget constraint, varying the severity of sea-level rise, and varying the risk (the range of possible sea-level rise). The details and the results from these robustness tests are presented in Appendix 1 and summarized in Table 3. The main conclusion from this analysis shows that incorporating sea-level rise into the decision-making framework provides a higher return/benefits compared to a myopic decision maker.

This highlights the inefficiencies (and the dangers) of ignoring sea-level rise predictions as has been proposed by for example by North Carolina. We next present a case study, based on data from Phippsburg, Maine, that demonstrates how to incorporate sea-level rise into coastal conservation planning and also the importance of doing so with regard to maximizing returns.

\section{Application: Wetlands in Phippsburg, Maine}

This section uses real data on potential wetland migration and property prices in Phippsburg, Maine to determine the optimal properties to purchase now in order to conserve wetlands in the future. While the specific results may only 
Table 3. Results from the Four Simulation Scenarios.

\begin{tabular}{llllll}
\hline & & Scenario 1 & Scenario 2 & Scenario 3 & Scenario 4 \\
\hline Budget & & 150 & $25-230$ & 150 & 10 \\
Mean Variation in Sea-Level Rise & & $50 \%$ & $50 \%$ & $10 \%$ to $90 \%$ & $50 \%$ \\
Range of Variation in Sea Level Rise & & $0 \%-100 \%$ & $0 \%-100 \%$ & $20 \%$ & $10 \%-50 \%$ \\
Difference in Benefits & Land units - Mean (SD) & $7(3.79)$ & $17.938(6.85)$ & 9 & $15 \%(7.26 \%)$ \\
& Percentage - Mean (SD) & $11 \%(8.76 \%)$ & $29.79 \%(4.14 \%)$ \\
& P-value & 0.061 & 0.00092 & 0.0015 & 0.0001 \\
Difference in Costs & Land units - Mean (SD) & $26(17.33)$ & N/A & N/A & N/A \\
& Percentage - Mean (SD) & $20 \%$ & & & \\
& P-value & 0.0001 & & & \\
\hline
\end{tabular}


be useful to those working in Phippsburg, the process used to find the results is easily transferable to other locations and data sets and will be useful for conservation agents in multiple settings.

\section{Why Maine, and Why Wetlands?}

Wetlands have recently been recognized as an incredibly valuable biome, both environmentally and economically. Their services include flood protection, maintenance of water quality (which can then be used for drinking water supplies), biodiversity support (which in turn provides recreational fishing and hunting opportunities), and carbon sequestration, making them one of Earth's most productive ecosystems (Heimlich et al. 1998, Birol, Karousakis, and Koundouri 2006). A study by Moore, Gunn and Troy (2012) placed a value of $\$ 1,399$ /acre/year (a total estimated value of $\$ 26,330,579$ ) for wetlands in Maine, excluding nonuse values. Unfortunately, their importance was not always understood, and wetlands have historically been drained or otherwise degraded on a national level (Barbier, Acreman, and Knowler 1997), making protection of those wetlands remaining especially important.

Recognizing this importance, multiple countries signed on to the Ramsar Convention in 1975, agreeing to include wetland conservation in national planning, among other requirements (Turner 1991). As of March 2016 there are 2,231 Ramsar wetland sites covering 2.1 million square kilometers globally. In the United States, the permits to dredge or fill in wetlands required by the Clean Water Act often require "compensatory wetland replacement," meaning wetlands elsewhere must be restored (Robertson 2006). While wetland conversion is an option to fulfil the requirement, protection and restoration has become the focus of federal wetland policy in an effort to balance the competing public and private interests arising from the public good quality wetlands poses (Heimlich et al. 1998). In addition to the national level efforts to protect wetlands coastal states, counties and cities also engage in wetland protection and management.

Maine has a substantial coastal community in terms of population, culture, and livelihoods. Compounding this, Maine is in a region expected to see sea levels rise higher than the global mean (Jones 2013), which has been predicted to increase by 0.5 to 1.4 meters above the 1990 level by 2100 (Rahmstorf 2007). The Sea Level Adaptation Working Group has predicted a 2 foot increase by 2100, a level now accepted by the Saco Bay, Maine region in their municipal planning (Sea Level Rise Adaptation Working Group 2011). Given these predictions and as a peninsular, open ocean town, Phippsburg, Maine has a particular need to understand the predictions and act accordingly. However, town meeting minutes show they have only recently begun to purposefully incorporate expectations of sea-level rise into their municipal planning process (Young 2012). 


\subsection{Introduction to the Marsh Migration Project}

In line with this focus on protection, in an effort to assist adaptation efforts by coastal communities in Maine, a collaborative effort between the Maine Coastal Program, Maine Department of Inland Fisheries and Wildlife, Maine Geological Survey, Wells National Estuarine Research Reserve, and Maine Coast heritage Trust, with support from a National Oceanic and Atmospheric Administration (NOAA) Project of Special Merit grant, was formed and named the Marsh Migration Team .

Six communities in Maine, namely Scarborough, Bath, Topsham, Phippsburg, Georgetown, and Bowdoinham, were selected for the project, which determined where current wetlands could potentially migrate to in each town under 1 foot, 2 foot, 3.3 foot, or 6 foot sea-level rise scenarios. A bathtub model, i.e., using elevation contours, was used to identify suitable areas (MMM 2013). ${ }^{2}$

We use the results of the Marsh Migration Team analysis for Phippsburg (Maine Geological Survey, Department of Agriculture, Conservation and Forestry 2014) for this work. The Phippsburg tax assessor supplied a GIS layer including all of the properties in Phippsburg as of 2011 and a text file including the total assessed value (including land and buildings) and acreage for each parcel for 2011 (Wilson-Hennessey, IFA, CMA, personal communication). Details of the data set up and merging are provided in Appendix 2.

\section{Data}

There are currently 35 non-island properties coded as conservation, land trust, or state property, with a total assessed value of $\$ 11,013,500$, protecting $1,858,969$ square meters (approximately 460 acres) of wetlands. These values are used as benchmarks for land area and budget. Property values for lots currently defined as conservation were set to zero, so they were automatically selected by the optimization method if they provided benefit in the future. This means the framework models the decision making of a conservation organization looking to protect additional land, given what is currently protected.

Aggregating the area of potential wetlands by map-lot type provides insights to the type of property these wetlands do or may lay on. The intersection found $3,424,802$ square meters (approximately 846 acres) of wetlands currently existing in Phippsburg. Of this area, 54 percent is under conservation, defined as a parcel coded as conservation, land trust, or state land. Future scenarios have significantly fewer potential wetlands, especially under two-foot or three-foot sea-rise levels. Of these areas for potential wetlands, about $1 / 5^{\text {th }}$ are already under conservation, requiring no further action to protect them.

\footnotetext{
2 A bathtub model assumes a uniform increase in sea levels and as such factors such as erosion and storm surge which may result from sea-level rise are not included in the analysis.
} 
Under the 1 foot sea-level rise scenario 32 percent is "not for sale," meaning it is on a current cemetery, a private or public road, is currently water, or is coded as unknown. The last type is of some concern for this analysis, as it may be land available for purchase or not (Juanita C. Wilson-Hennessey, IFA, CMA, personal communication). See Figure 1 and Table 4 for further details.

The spatial distribution of property values in Phippsburg is important to understand. As seen in Figure 2, property values tend to be higher on the western and southern sides of the peninsula, as properties are on the open coast. On the eastern side is the Kennebec River, which creates wetlands as well but does not tend to cause property values to increase by as great a degree. This pattern likely explains the results seen in the set-coverage optimizations.

Most of the current conservation land (Conservation, Land Trust, or State Land) has either a current or potential wetland. Figure 3 provides a spatial distribution of these properties.

\section{Simulation Scenarios}

Because there may be fewer wetlands in the future, it will be impossible to achieve the same level of protection at any cost. Therefore, in the first model we target conserving approximately 5-20 percent of current coverage under

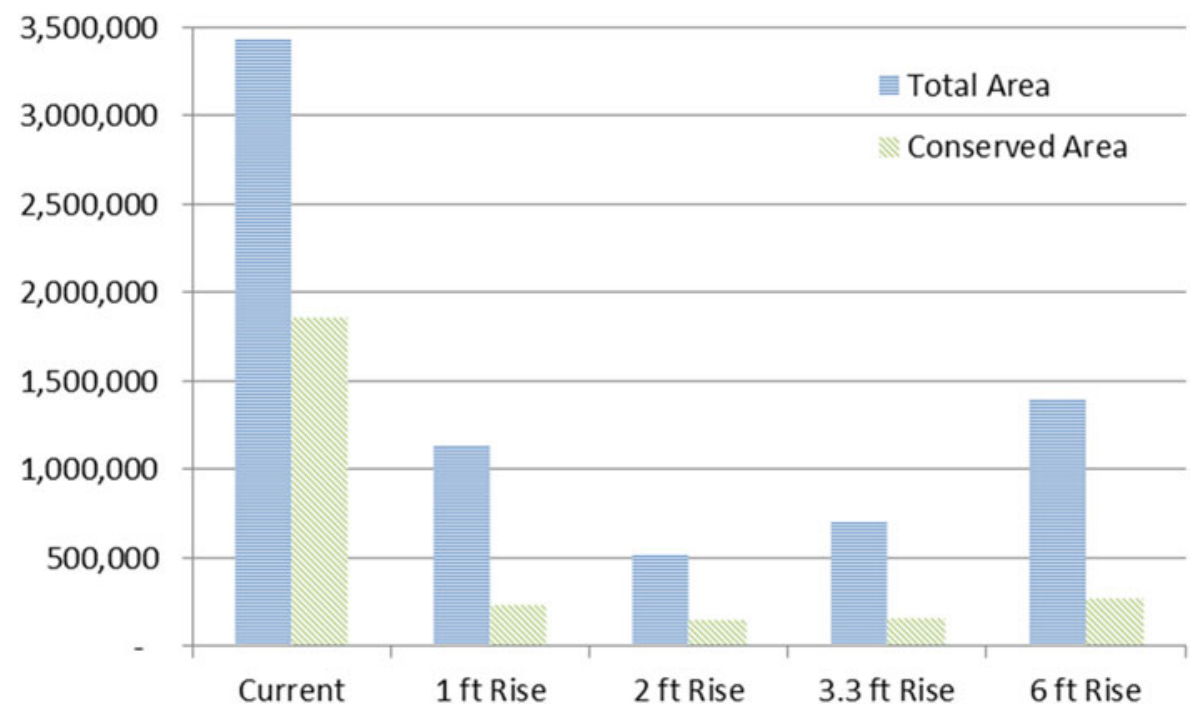

Figure 1. The Area of Current or Potential Future Wetlands under Each of the Analyzed Sea-Level Rise Scenarios. Blue Represents the Total Area, While Green Represents the Area of Conserved Wetlands, if no Further Parcels Are Protected. 
Table 4. Aggregation of Wetland Area by Current Map-Lot Type, as Coded in the GIS layer, for Each Sea-Level Rise Scenario. Area is in Square Meters, and Percentages Are of the Sum for that Sea-Level Rise Scenario.

\begin{tabular}{|c|c|c|c|c|c|}
\hline Land Type & Current & $1 \mathrm{ft}$ Rise & $2 \mathrm{ft}$ Rise & $3.3 \mathrm{ft}$ Rise & $6 \mathrm{ft}$ Rise \\
\hline \multirow{2}{*}{ Cemetery } & 0 & 10 & 7 & 6 & 34 \\
\hline & $0.00 \%$ & $0.00 \%$ & $0.00 \%$ & $0.00 \%$ & $0.00 \%$ \\
\hline \multirow[t]{2}{*}{ Common } & 12,881 & 2,627 & 1,779 & 2,236 & 7,716 \\
\hline & $0.38 \%$ & $0.23 \%$ & $0.34 \%$ & $0.31 \%$ & $0.55 \%$ \\
\hline \multirow[t]{2}{*}{ Conservation } & 926,069 & 129,177 & 98,381 & 109,575 & 163,782 \\
\hline & $27.04 \%$ & $11.43 \%$ & $19.03 \%$ & $15.43 \%$ & $11.68 \%$ \\
\hline \multirow[t]{2}{*}{ Federal } & 0 & 668 & 603 & 1,036 & 1,780 \\
\hline & $0.00 \%$ & $0.06 \%$ & $0.12 \%$ & $0.15 \%$ & $0.13 \%$ \\
\hline \multirow[t]{2}{*}{ Island } & 1,756 & 15,597 & 14,208 & 19,988 & 44,768 \\
\hline & $0.05 \%$ & $1.38 \%$ & $2.75 \%$ & $2.81 \%$ & $3.19 \%$ \\
\hline \multirow[t]{2}{*}{ Land Trust } & 155,529 & 25,316 & 9,238 & 11,337 & 23,018 \\
\hline & $4.54 \%$ & $2.24 \%$ & $1.79 \%$ & $1.60 \%$ & $1.64 \%$ \\
\hline \multirow[t]{2}{*}{ Open Space } & 0 & 1 & 3 & 5 & 54 \\
\hline & $0.00 \%$ & $0.00 \%$ & $0.00 \%$ & $0.00 \%$ & $0.00 \%$ \\
\hline \multirow[t]{2}{*}{ Parcel } & $1,500,000$ & 504,411 & 306,623 & 460,485 & 929,157 \\
\hline & $43.80 \%$ & $44.62 \%$ & $59.32 \%$ & $64.83 \%$ & $66.23 \%$ \\
\hline \multirow[t]{2}{*}{ Private Road } & 3,274 & 2,342 & 2,627 & 1,328 & 3,618 \\
\hline & $0.10 \%$ & $0.21 \%$ & $0.51 \%$ & $0.19 \%$ & $0.26 \%$ \\
\hline \multirow[t]{2}{*}{ ROW } & 0 & 3,341 & 5,472 & 3,957 & 3,526 \\
\hline & $0.00 \%$ & $0.30 \%$ & $1.06 \%$ & $0.56 \%$ & $0.25 \%$ \\
\hline \multirow[t]{2}{*}{ Road } & 8,173 & 17,421 & 16,247 & 15,151 & 29,108 \\
\hline & $0.24 \%$ & $1.54 \%$ & $3.14 \%$ & $2.13 \%$ & $2.07 \%$ \\
\hline \multirow[t]{2}{*}{ State } & 777,371 & 72,359 & 41,310 & 39,358 & 80,371 \\
\hline & $22.70 \%$ & $6.40 \%$ & $7.99 \%$ & $5.54 \%$ & $5.73 \%$ \\
\hline \multirow[t]{2}{*}{ Town } & 3,306 & 10,740 & 8,523 & 6,491 & 9,551 \\
\hline & $0.10 \%$ & $0.95 \%$ & $1.65 \%$ & $0.91 \%$ & $0.68 \%$ \\
\hline \multirow[t]{2}{*}{ Unknown } & 4,381 & 1,455 & 2,817 & 5,493 & 3,884 \\
\hline & $0.13 \%$ & $0.13 \%$ & $0.55 \%$ & $0.77 \%$ & $0.28 \%$ \\
\hline \multirow[t]{2}{*}{ Water } & 32,062 & 345,031 & 9,026 & 33,809 & 102,452 \\
\hline & $0.94 \%$ & $30.52 \%$ & $1.75 \%$ & $4.76 \%$ & $7.30 \%$ \\
\hline SUM & $3,424,802$ & $1,130,496$ & 516,864 & 710,255 & $1,402,819$ \\
\hline \multirow[t]{2}{*}{ "Conservation" } & $1,858,969$ & 226,852 & 148,929 & 160,270 & 267,171 \\
\hline & $54.28 \%$ & $20.07 \%$ & $28.81 \%$ & $22.57 \%$ & $19.05 \%$ \\
\hline \multirow[t]{2}{*}{ Not for Sale } & 47,890 & 369,600 & 36,196 & 59,744 & 142,622 \\
\hline & $1.40 \%$ & $32.69 \%$ & $7.00 \%$ & $8.41 \%$ & $10.17 \%$ \\
\hline
\end{tabular}

each sea-level-rise scenario. Specifically we find the minimum cost to cover the stated land area. This is the canonical set-covering problem as defined in the reserve design/systematic conservation literature. 


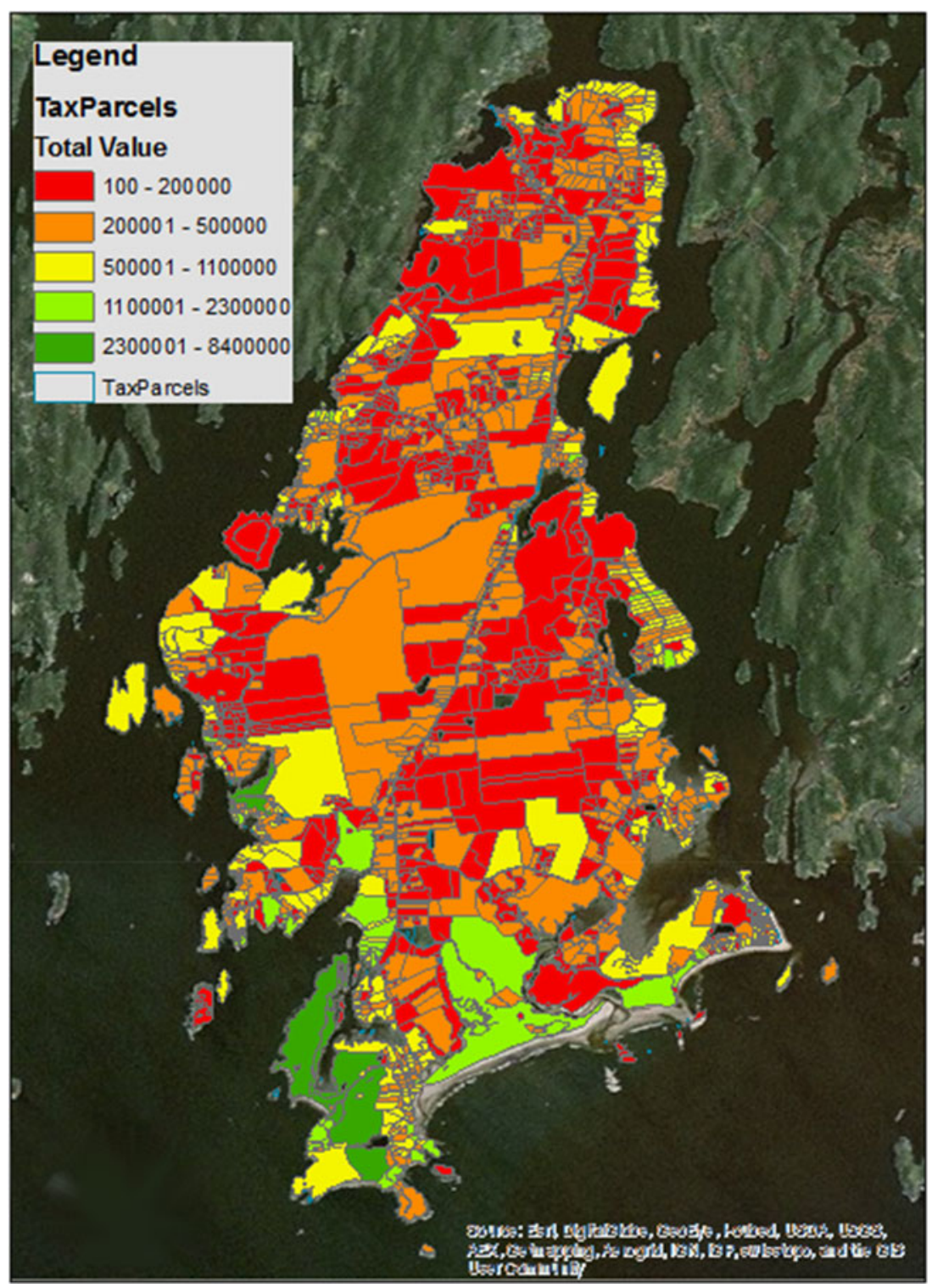

Figure 2. Spatial Distribution of Property Values in Phippsburg, Maine. To the West and South is Open Coast, While the Kennebec River is to the East.

In the second model, we find the maximum potential area of wetlands conserved under a range of budgets. This is the canonical maximal-covering problem as defined in the reserve design/systematic conservation literature. For this scenario, following Ando and Mallory (2012), we account for 


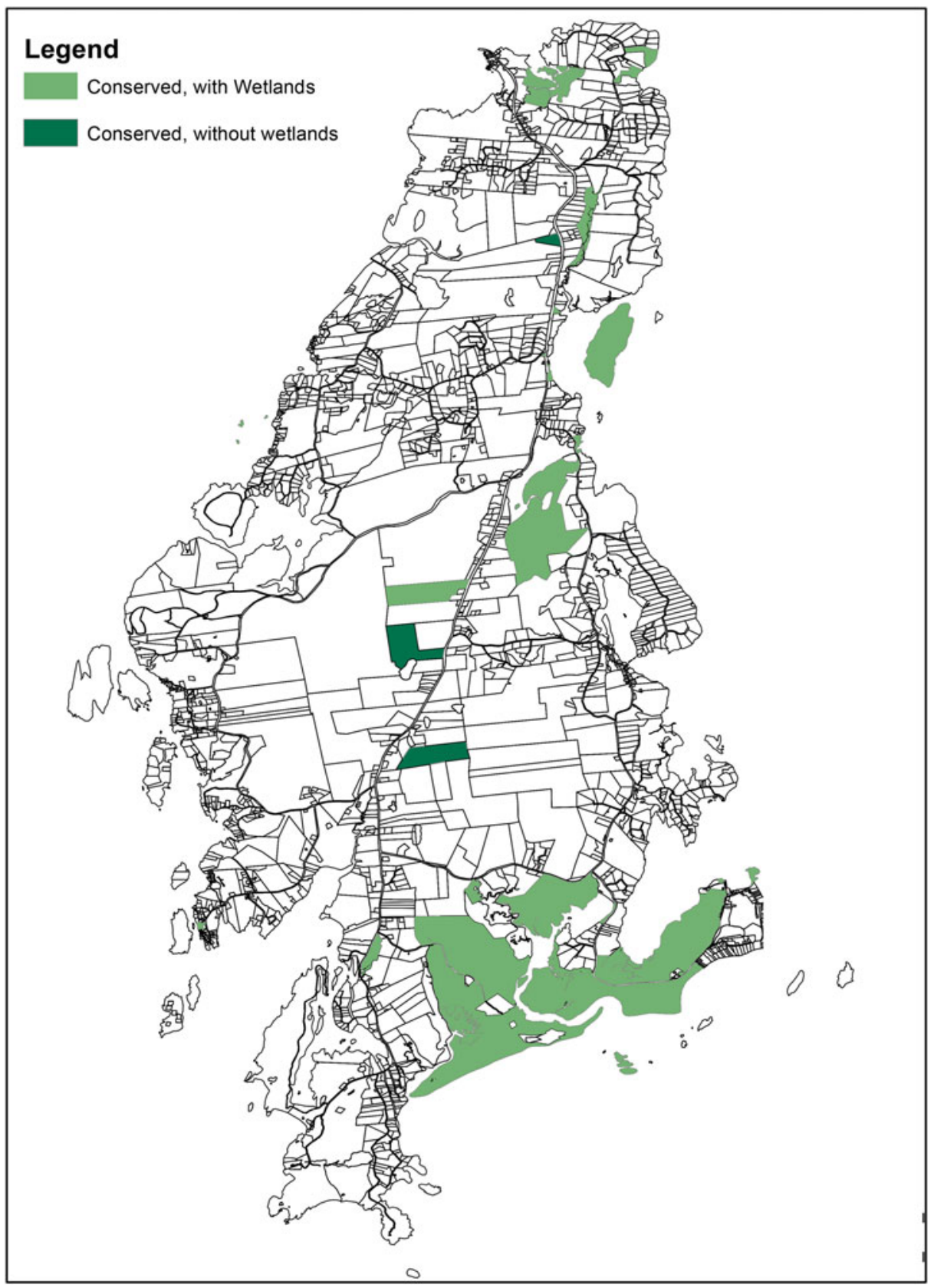

Figure 3. Currently Conserved (Meaning Conservation, Land Trust, or State Land) in Phippsburg, and Whether that Property Has Current or Potential Wetlands (Light Green) or Not (Dark Green). 
different climate scenarios by multiplying the potential area of wetlands by a probability distribution for the four sea-level-rise scenarios analyzed. The probability distributions used were an even distribution $(0.25 / 0.25 / 0.25 /$ 0.25 ), a $.7 / .1 / .1 / .1$ distribution, a $.1 / .1 / .7 / .1$ distribution, and a $.4 / .4 / .1 / .1$ distribution, where the probabilities correspond to 1-foot, 2-foot, 3.3-foot, and 6-foot rises, respectively.

In both optimization models, the assessed value for each map-lot was used as a proxy for purchasing cost. These values could change with sea-level rise, either positively or negatively, but as the decision framework is intended for an organization making purchases today the analysis does not incorporate changes in future prices of the land. Also for both optimization models, we use the size of the potential wetland area as the benefit of conservation. This is a simplification, and if an organization wanted to focus on specific wetland types or locations or ecosystem based benefits the decision-making framework can easily be adopted to do so by replacing the size by the desired benefits.

\section{Model 1: Set Covering}

As is typical in conservation site selection models we see that under every sealevel-rise scenario the costs increase as a function of the conserved area (see Figure 4). In this application the cost increase is exponential, and this may be explained by the limited area of wetlands available and the distribution of property values in Phippsburg. For example, to go from conserving 400,000 square meters ( 98.8 acres) to 500,000 square meters ( 123.5 acres) under the 3.3 -foot sea-level-rise scenario, the cost increases from $\$ 12,470,300$ to $\$ 47,490,900$, while the number of properties selected increases from 109 to 202 (including the 35 properties currently conserved). To allow for the possibility of using the current conservation land to fund the purchase of future conservation land, we include the current value of conservation land in Figure 4. This shows that conservation of more than $500,000 \mathrm{~m}^{2}(123.5$ acres) in the future is unlikely, with conservation under the 6-foot scenario being the only possible exception.

To explore the hypothesis that the distribution of land prices is driving the exponential cost increases seen in Figure 4, we examine the potentially extreme case of moving from 400,000 square meters of wetlands conserved to 500,000 square meters of wetlands conserved under the 3.3-foot sea-level rise scenario. To do this, the map-lots selected by the optimization algorithm in both cases were mapped using ArcMap and compared. As illustrated in Figure 5, many of the properties selected when covering 500,000 square meters are on the eastern, western, and southern portions of Phippsburg, while the properties selected when covering 400,000 square meters are mainly confined to the eastern portion of Phippsburg. Recall the properties on the southern and western portions of Phippsburg are the most expensive, supporting the hypothesis that this is a driving force in the cost structure seen. Essentially, as the conservation organization increases amount of land 


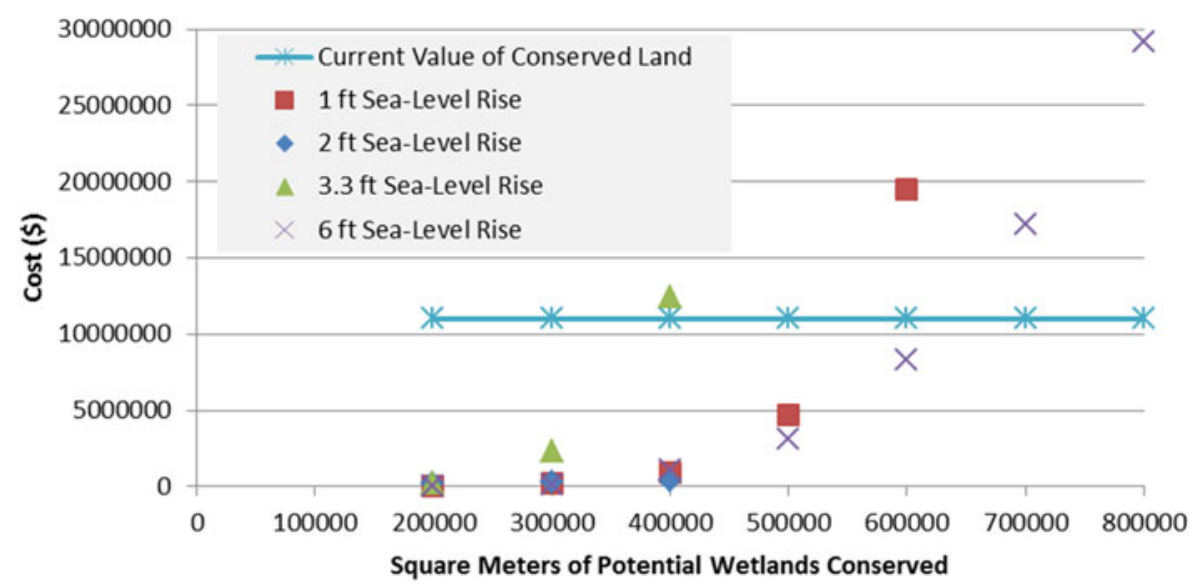

Figure 4. Minimum Cost to Conserve a Given Area of Potential Wetlands under Each Sea-Level Rise Scenario. The Cost of Currently Conserved Parcels Was Set to Zero. Coverage Of $500,000 \mathrm{M}^{2}$ under a 3.3-Foot Rise is Possible, but at a Cost Higher Than the Range of This Figure.

being protected, the conservation organization reaches a point where it is being forced to buy almost any property with benefits, regardless of the cost.

Finally, as seen in Figure 6, there are some properties which would be selected for a set level of coverage under both the minimum and maximum levels of sea-level rise. These colors are shown in beige, while parcels selected for only a 1 -foot rise or only a 6-foot rise are shown according to the legend. The properties which are selected under more than one scenario may be of increased value to conservation organizations, considering the uncertainty involved in predicting what sea-level-rise scenario to expect, since they are expected to provide coverage no matter what sea-level-rise scenario actually occurs.

\section{Model 2: Maximal Covering}

Maximizing the total area conserved, given various probability distributions for the four sea-level-rise scenarios examined, showed decreasing marginal returns to the budget in all cases (Figure 7), as is the standard result for maximal covering problems. This corresponds to the results found in the set-coverage optimization method, which also show decreasing marginal returns. The maximal covering problem highlights that the greatest expected benefits are when the smallest sea-level-rise levels were the most likely, although the differences between each distribution is fairly small.

We map the properties selected by the maximal covering selection under all four of the probability distributions. We use a budget of $\$ 250,000$ in the 


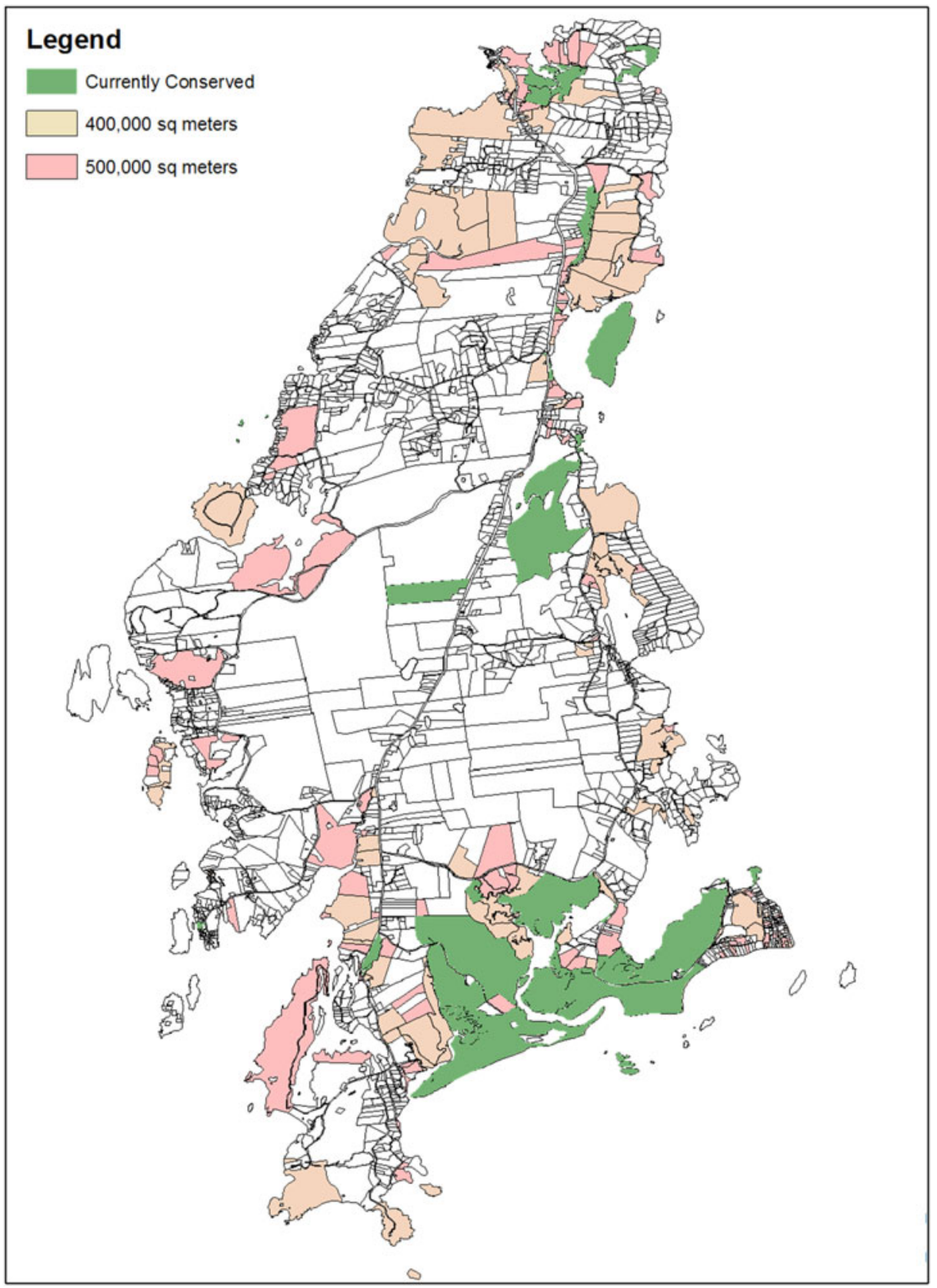

Figure 5. Visual Representation of Parcels Selected by Set Coverage Optimization Method for Conservation of 400,000 and 500,000 Square Meters of Potential Wetlands under the 3.3-Foot Sea-Level Rise scenario. 


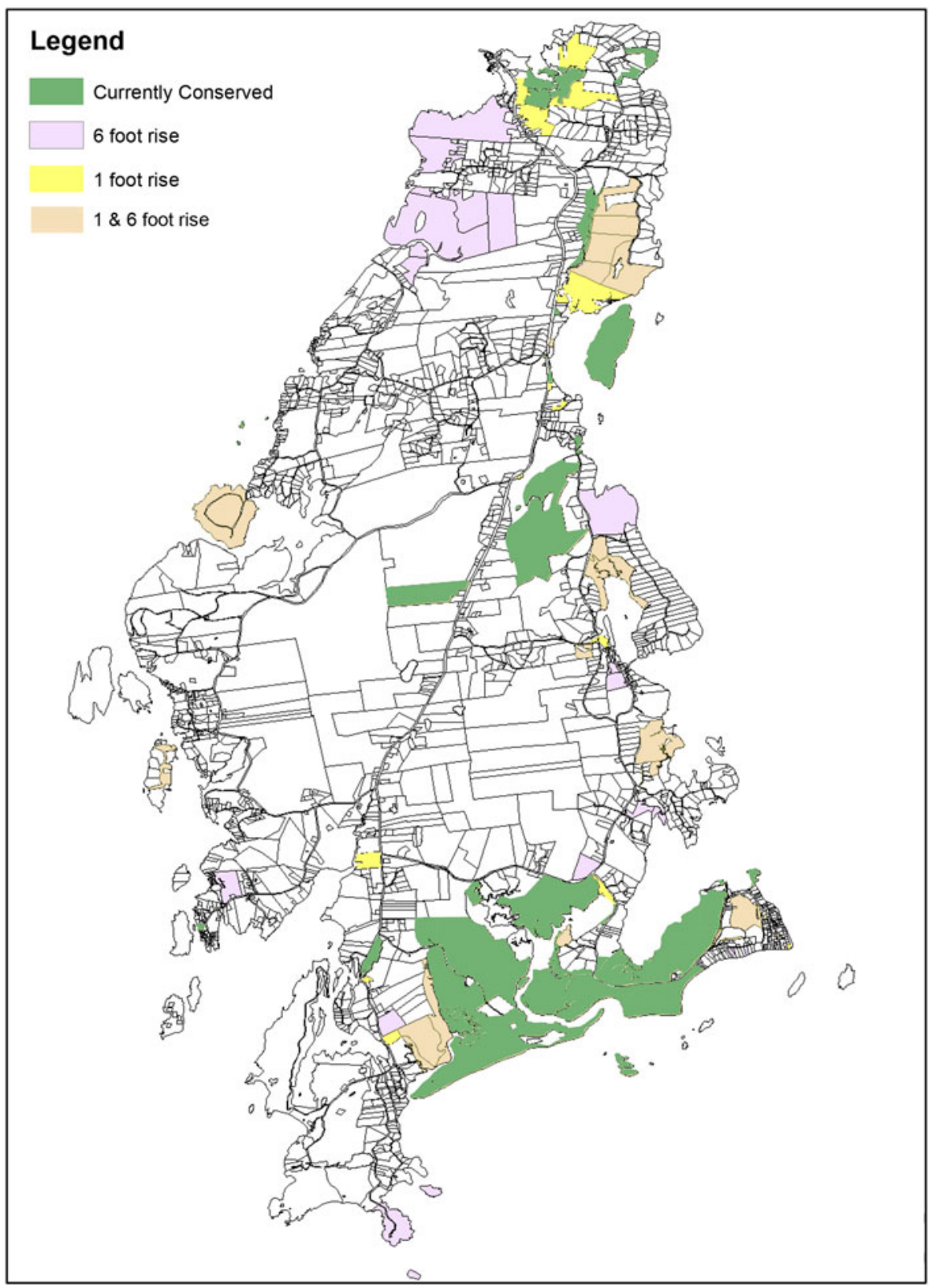

Figure 6. Selected Sites to Cover 500,000 Square Meters of Potential Wetlands under a 1-Foot Or 6-Foot Sea-Level-Rise Scenario. Sites Selected in Both Scenarios are Shown in Beige, Sites Only Selected under a 1-Foot Rise Are in Yellow, and Sites Only Selected under a 6-Foot Rise Are in Purple. 


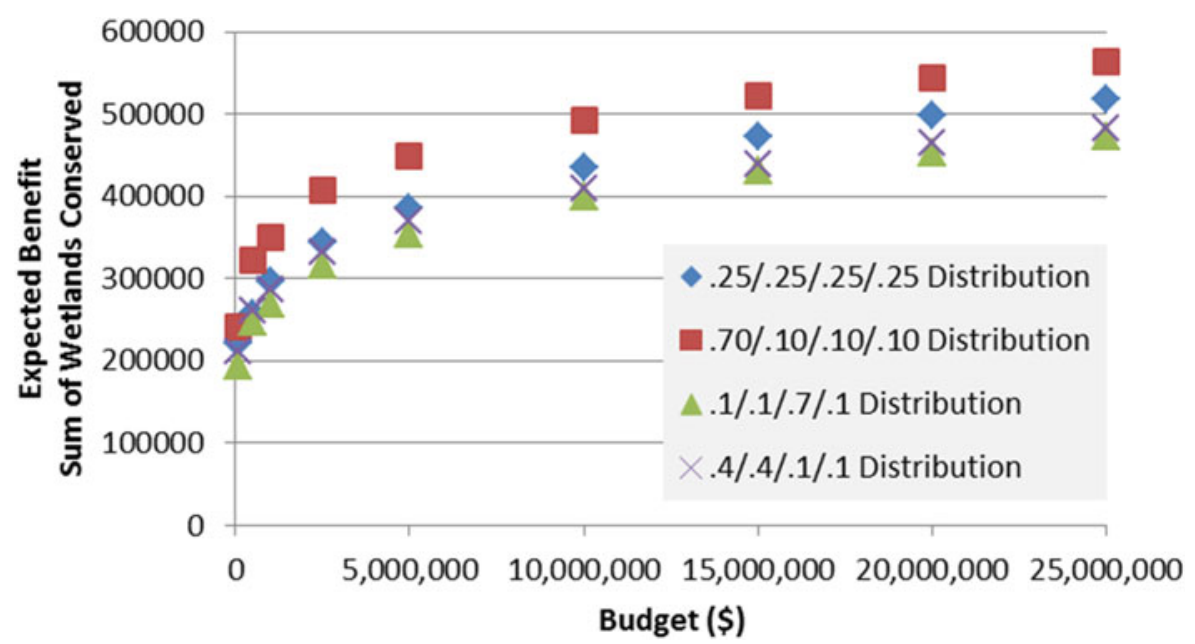

Figure 7. Expected Conservation Benefits under Various Sea-Level-Rise Probability Distributions.

presented results. First, in Figure 8, the sites selected under an even distribution $(.25 / .25 / .25 / .25)$ are shown in pink, the sites selected under the $.7 / .1 / .1 / .1$ distribution are shown in yellow, and the sites selected under both distributions are shown in orange. Second, in Figure 9, the sites selected under the .1/.1/.7/.1 distribution are shown in pink, the .4/.4/.1/.1 distribution is shown in light blue, and the sites selected in both are shown in a deep blue color. By comparing these two maps, it can also be seen that several properties are selected under more than one distribution, again indicating that they may be especially beneficial for conservation organizations to conserve. It is also interesting to note that very few properties were selected along the open coast under any of the scenarios. This supports the hypothesis that the high cost of these properties outweighs any benefits they have.

In summary, we use set covering and maximal covering models to identify the best land to purchase for future wetlands in Phippsburg, Maine, given a range of probabilities of climate outcomes. We then generate specific maps from these results to highlight how conservation organizations can incorporate climatechange-based land-use changes into coastal conservation planning.

\section{Discussion and Conclusion}

Current climate models generally predict rising sea levels, although the specific level of the increase in any given location is uncertain (IPCC 2013). Not only will sea-level rise continue to occur, it is expected to increase at an increasing rate as we move further into this century. Given this, it seems intuitive that 


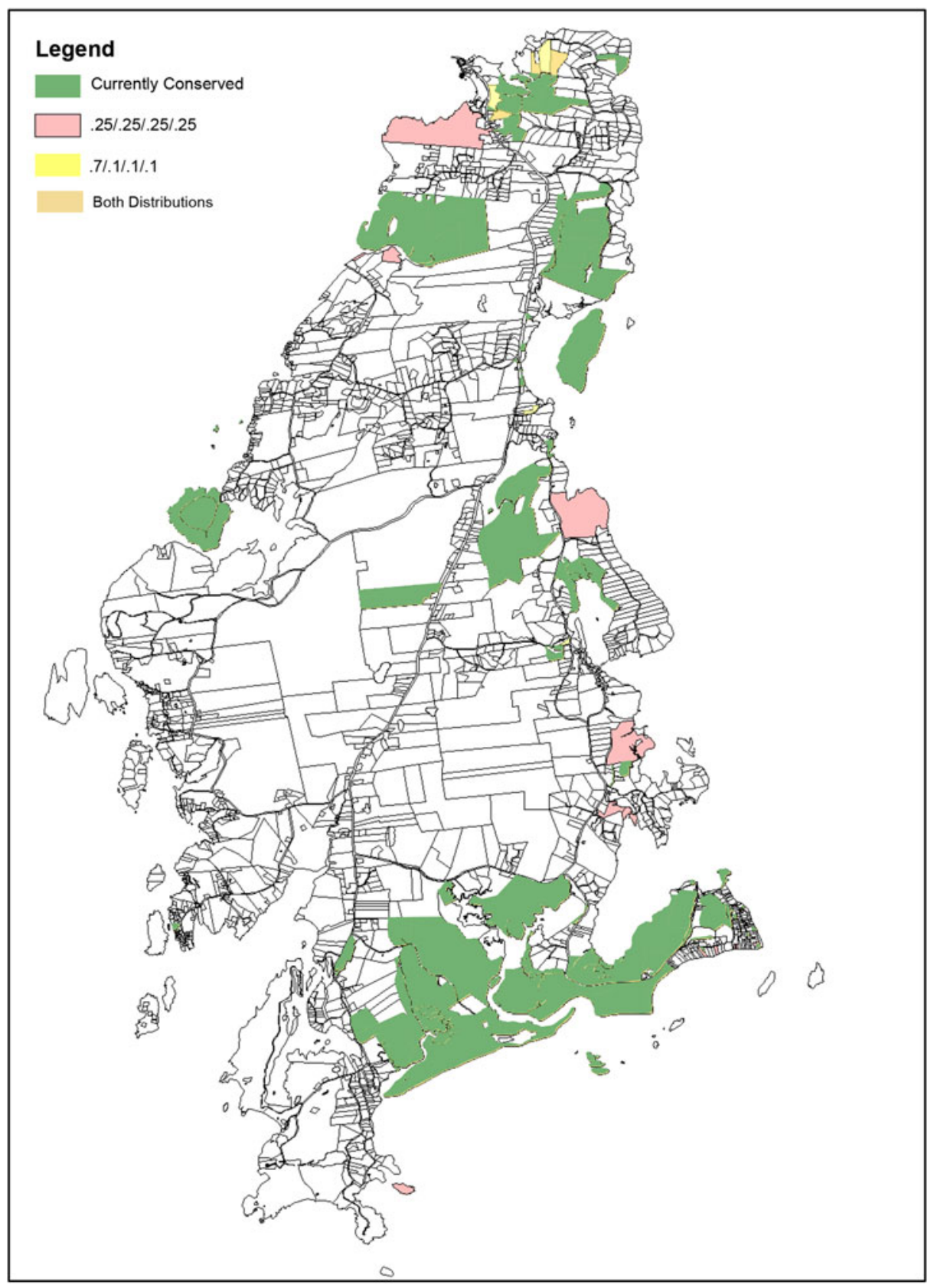

Figure 8. Selected Sites for a Budget of $\$ 250,000$ (about 300,000 Square Meters) Given Two Selected Probability Distributions. Sites Selected in Both Distributions are Shown in Orange. 


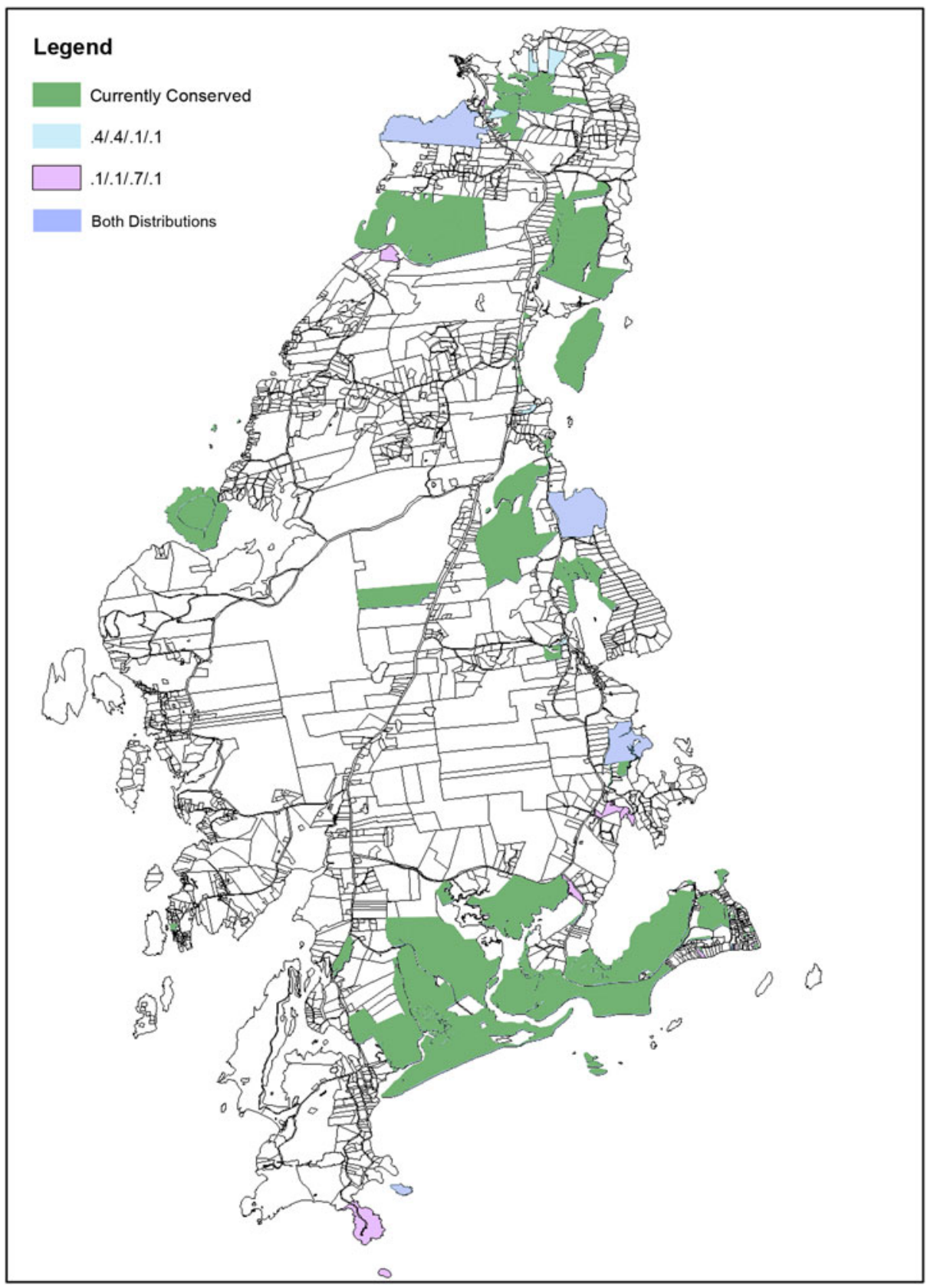

Figure 9. Selected Sites for a Budget of $\$ 250,000$ (about 300,000 Square Meters) Given Two Selected Probability Distributions. Sites Selected in Both Distributions are Shown in Purple. 
incorporating expectations of sea-level rise into decision making would result in increased benefits; this is evident from the results using simulated data with the knapsack method. Our results highlight the importance of incorporating sealevel rise information in decision making vs. the myopic approach of ignoring predictions, as has been evident in some cases, including with the legislation in North Carolina.

In our simulation analysis, we find conservation agencies are able to increase benefits between 11 percent to almost 30 percent by incorporating sea-level rise into their decision making. The benefits from anticipating sea-level rise are actually greatest with a mid-range budget, when conditions are uncertain, and when the risk is greatest. Arguably, these conditions are the same as those being faced by conservation organizations today. We then present a case study and highlight methods that can be adopted by coastal conservation agencies.

Using Phippsburg, Maine as a case study to select the optimal properties given either a budget and probability distributions of sea-level rise, or a set coverage goal under each sea-level-rise scenario generated results that can help the town and conservation agencies plan their future land purchases. In general, Phippsburg is faced with decreasing marginal returns relative to the size of the conservation budget, a result that is common in many site-selection studies. The properties in Phippsburg, Maine have a positive correlation between property prices and coastal acreage, and this correlation also means fewer wetlands may be conserved if the goal is storm surge protection, necessitating purchasing properties along the open coast.

The method used to analyze Phippsburg highlights one approach that conservation organizations may be able to use to explore what parcels would be optimal to purchase (given their respective goals). With fewer computational requirements than some of the methods currently in the literature, the approach we present is especially appealing, as it can be replicated using free or inexpensive versions of ArcMap or QGIS for the GIS component, and Excel, a standard program that organizations are likely to already have, for the optimization work.

However, the method we used for this study requires detailed data which may be difficult to obtain in some cases. Phippsburg already had tax maps as GIS layers, something many Maine towns have not yet done. The Marsh Migration Team also put considerable work into ground truthing and conducting their analysis of potential wetland migration, supported by grant money. The method used here also partially takes into account the issue of land availability, in that public and private roads, as well as current water bodies, were identified and left out of the analysis. On the other hand, our analysis not only considered all other properties as "for sale," it considered them as for sale at the assessed value, an unrealistic assumption given some individuals' reluctance to part with their home, even if they would be compensated above market price. This issue of land availability is something that should be appropriately accounted for in future work. 
Overall, our study presents a potential decision-making method for conservation organizations, which may be less computationally demanding and therefore may be more useful for decision makers than methods used in the literature. Sites selected under multiple selection criteria may be of particular interest to conservation organizations. Educational efforts could be streamlined using this method, up to the optimization step, to identify who owns properties that could be converted to wetlands in the future. Finally, the method was successful in generating useful results using real data, showing that it could be used to inform a real decision in a similar setting.

\section{References}

Ando, A.W., J. Camm, S. Polasky, and A. Solow. 1998. "Species Distributions, Land Values, and Efficient Conservation." Science 279(5359): 2126-2128.

Ando, A.W., and L. Hannah. 2011. "Lessons from Finance for New Land-Conservation Strategies Given Climate-Change Uncertainty." Conservation Biology 25(2): 412-414.

Ando, A.W, and M.L. Mallory. 2012. "Optimal Portfolio Design to Reduce Climate-Related Conservation Uncertainty in the Prairie Pothole Region." Proceedings of the National Academy of Sciences 109(17): 6484-6489.

Armsworth, P.R, G.C. Daily, P. Kareiva, and J.N. Sanchirico. 2006. "Land Market Feedbacks Can Undermine Biodiversity Conservation." Proceedings of the National Academy of Sciences 103(14): 5403-5408.

Arthur, J.L., J.D. Camm, R.G. Haight, C.A. Montgomery, and S. Polasky. 2004. "Weighing Conservation Objectives: Maximum Expected Coverage versus Endangered Species Protection.” Ecological Applications 14(6): 1936-1945.

Barbier, E.B., M. Acreman, and D. Knowler. 1997. "Economic Valuation of Wetlands: A Guide for Policy Makers and Planners."

Birol, E., K. Karousakis, and P. Koundouri. 2006. "Using a Choice Experiment to Account for Preference Heterogeneity in Wetland Attributes: The Case of Cheimaditida Wetland in Greece." Ecological Economics. 60(1): 145-156.

Boyd, J., R. Epanchin-Niell, and J. Siikamäki. 2015. "Conservation Planning: A Review of Return on Investment Analysis." Review of Environmental Economics and Policy 9(1): 23-42.

Camm, J.D., S. Polasky, A. Solow, and B. Csuti. 1996. "A Note on Optimal Algorithms for Reserve Site Selection." Biological Conservation 78(3): 353-355.

Cerdeira, J.O., K.J. Gaston, and L.S. Pinto. 2005. "Connectivity in Priority Area Selection for Conservation." Environmental Modeling \& Assessment. 10(3): 183-192.

Church, R., and Charles, R.V. 1974. "The Maximal Covering Location Problem." Papers in Regional Science 32(1): 101-118.

Costello, C., and S. Polasky. 2004. "Dynamic Reserve Site Selection." Resource and Energy Economics. 26(2): 157-174.

Cova, T.J., and R.L. Church. 2000. "Contiguity Constraints for Single-Region Site Search Problems." Geographical Analysis 32(4): 306-329.

Dissanayake, S.T.M., H. Onal, and J.D. Westervelt. 2011. "Optimum Selection of Conservation Reserves: Extensions to Multiple Land Use." Military Operations Research. 16(1): 65-76.

Dissanayake, S.T.M., and H. Önal. 2011. "Amenity Driven Price Effects and Conservation Reserve Site Selection: A Dynamic Linear Integer Programming Approach." Ecological Economics. 70(12): 2225-2235.

Dissanayake, S. T.M., H. Önal, J.D. Westervelt, and H.E. Balbach. 2012. "Incorporating Species Relocation in Reserve Design Models: An Example from Ft. Benning GA." Ecological Modelling. 224(1): 65-75. 
Elton, E.J., and M.J. Gruber. 1997. “Modern Portfolio Theory, 1950 to Date.” Journal of Banking \& Finance 21(11): 1743-1759.

Fischer, D.T., and R.L. Church. 2003. "Clustering and Compactness in Reserve Site Selection: an Extension of the Biodiversity Management Area Selection Model." Forest Science 49(4): 555-565.

Fox News. 2010. "White House: Global Warming Out, 'Global Climate Disruption' In.” Fox News, accessed 6/27/2017.

Haight, R.G., and S.A. Snyder. 2009. "Integer Programming Methods for Reserve Selection and Design.” In A. Moilanen, K.A. Wilson, and H.P. Possingham, eds., Spatial Conservation Prioritization: Quantitative Methods And Computational Tools. New York, NY: Oxford University Press.

Heimlich, R.E., K.D. Wiebe, R. Claassen, D. Gadsby, and R.M. House. 1998. "Wetlands and Agriculture: Private Interests and Public Benefits." Agricultural Economics Report 765.

Holdren, J.P. 2010. Climate-Change Science and Policy: What Do We Know? What Should We Do? Executive Office of the President, Washington, DC, Office of Science and Technology Policy.

IPCC, 2013. Summary for Policymakers. T.F. Stocker, D. Qin, G.-K. Plattner, M. Tignor, S.K. Allen, J. Boschung, A. Nauels, Y. Xia, V. Bex and P.M. Midgley, Eds. Climate Change 2013: The Physical Science Basis. Contribution of Working Group I to the Fifth Assessment Report of the Intergovernmental Panel on Climate Change. Cambridge, UK and New York, NY, USA: Cambridge University Press.

Jones, N. 2013. “Rising Tide." Nature 501(7467): 300.

Kirkpatrick, J.B. 1983. “An Iterative Method for Establishing Priorities for the Selection of Nature Reserves: An Example from Tasmania." Biological Conservation. 25(2): 127-134.

Krakauer, H. 2012. "North Carolina Tries to Outlaw Climate Models." New Scientist. (17)55.

Lee, J. 2012. "Legislating Sea Level Rise." Science Magazine.

Lontzek, T. S., and D. Narita. 2011. "Risk-Averse Mitigation Decisions in an Unpredictable Climate System." The Scandinavian Journal of Economics 113(4): 937-958.

Maine Climate Initiatives. 2014. "Integrating Science into Policy: Adaptation Strategies for Marsh Migration." Gulf of Maine Council's Climate Network.

Maine Geological Survey. 2014. Sea Level Rise and Storm Surge Scenarios: Phippsburg, ME. Augusta, ME: Maine Geological Survey, Department of Agriculture, Conservation and Forestry.

Marsh Migration Meeting (MMM). 2013. "Marsh Migration Meeting."

Moilanen, A., and I. Ball. 2009. "Heuristic and Approximate Optimization Methods for Spatial Conservation Prioritization." In A. Moilanen, K.A. Wilson, H.P. Possingham, eds., Spatial Conservation Prioritization: Quantitative Methods and Computational Tools. New York, NY: Oxford University Press.

Moilanen, A. and M. Cabeza. 2002. "Single-Species Dynamic Site Selection." Ecological Applications. 12(3): 913-926.

Moore, R., J. S. Gunn, and A. Troy. 2012. "Valuing Maine's Nature." In Natural Capital Initiative at Manomet Report. Brunswick, ME: Natural Capital Initiative.

Naidoo, R., A. Balmford, P.J. Ferraro, S. Polasky, T.H. Ricketts, and M. Rouget. 2006. "Integrating economic Costs into Conservation Planning." Trends in Ecology \& Evolution. 21(12): 681-687.

Nelson, E., G. Mendoza, J. Regetz, S. Polasky, H. Tallis, D.R. Cameron, K. Chan, G.C. Daily, J. Goldstein, and P.M. Kareiva. 2009. "Modeling Multiple Ecosystem Services, Biodiversity Conservation, Commodity Production, and Tradeoffs at Landscape Scales." Frontiers in Ecology and the Environment 7(1): 4-11.

Newburn, D.A., P. Berck, and A.M. Merenlender. 2006. "Habitat and Open Space at Risk of Land-Use Conversion: Targeting Strategies for Land Conservation." American Journal of Agricultural Economics. 88(1): 28-42. 
Nicholls, R. J., F. M. J. Hoozemans, and M. Marchand. 1999. “Increasing Flood Risk and Wetland Losses Due to Global Sea-Level Rise: Regional and Global Analyses." Global Environmental Change. 9: S69-S87.

Önal, H. 2004. "First-Best, Second-Best, and Heuristic Solutions in Conservation Reserve Site Selection." Biological Conservation 115(1): 55-62.

Önal, H., and R.A. Briers. 2003. "Selection of a Minimum-Boundary Reserve Network using Integer Programming." Proceedings of the Royal Society of London B: Biological Sciences. 270(1523): 1487-1491.

- 2006. "Optimal selection of a connected reserve network." Operations Research. 54(2): 379-388.

Önal, H., and Y. Wang. 2008. "A Graph Theory Approach for Designing Conservation Reserve Networks with Minimal Fragmentation." Networks. 51(2): 142-152.

Önal, H., Y. Wang, S. T.M. Dissanayake, and J.D. Westervelt. 2016. "Optimal Design of Compact and Functionally Contiguous Conservation Management Areas." European Journal of Operational Research. 251(3): 957-968.

Polasky, S., J.D Camm, A.R. Solow, B. Csuti, D. White, and R. Ding. 2000. “Choosing Reserve Networks with Incomplete Species Information." Biological Conservation 94(1): 1-10.

Possingham, H., I. Ball, and S. Andelman. 2000. "Mathematical Methods for identifying Representative Reserve Networks." In Quantitative Methods For Conservation Biology, 291-306. New York: Springer.

Prendergast, J.R., R.M. Quinn, and J.H. Lawton. 1999. "The Gaps Between Theory and Practice in Selecting Nature Reserves." Conservation Biology 13(3):484-492.

Rahmstorf, S. 2007. “A Semi-Empirical Approach to Projecting Future Sea-Level Rise." Science. 315(5810): 368-370.

Robertson, M.M. 2006. "Emerging Ecosystem Service Markets: Trends in a Decade of Entrepreneurial Wetland Banking." Frontiers in Ecology and the Environment. 4(6): 297-302.

Rodrigues, A.S.L., and K.J. Gaston. 2002. "Optimisation in Reserve Selection Procedures-Why Not?” Biological Conservation. 107(1): 123-129.

Sabbadin, R., D. Spring, and C. Rabier. 2007. “Dynamic Reserve Site Selection under Contagion Risk Of Deforestation.” Ecological Modelling 201(1): 75-81.

Sea Level Rise Adaptation Working Group 2011. Sea Level Rise and Potential Impacts by the Year 2100. In M.G. Survey \& S.M.R.P. Commission, eds., A Vulnerability Assessment for the Saco Bay Communities of Biddeford, Saco, Old Orchard Beach, and Scarborough. Saco, ME.

Shah, P., and A.W. Ando. 2015. "Downside versus symmetric measures of uncertainty in natural resource portfolio design to manage climate change uncertainty." Land Economics 91(4): 664-687.

Snyder, S.A, Robert, G.H., and C.S. ReVelle. 2005. "A Scenario Optimization Model for Dynamic Reserve Site Selection." Environmental Modeling and Assessment 9(3): 179-187.

Strange, N., J.B. Jacobsen, B.J. Thorsen, and P. Tarp. 2007. "Value for Money: Protecting Endangered Species on Danish Heathland." Environmental Management 40(5): 761-774.

Strange, N., B.J. Thorsen, and J. Bladt. 2006. “Optimal Reserve Selection in a Dynamic World." Biological Conservation 131(1): 33-41.

Toregas, C., and C. Revelle. 1973. "Binary Logic Solutions to a Class of Location Problem." Geographical Analysis 5(2): 145-155.

Turner, K. 1991. "Economics and Wetland Management." Ambio. 20(2): 59-63.

Underhill, L.G. 1994. "Optimal and Suboptimal Reserve Selection Algorithms." Biological Conservation. 70(1):85-87.

Williams, J.C., and C.S. ReVelle. 1996. "A 0-1 Programming Approach To Delineating Protected Reserves." Environment and Planning B: Planning and Design. 23(5):607-624.

Williams, J.C. 2002. "A Zero-One Programming Model for Contiguous Land Acquisition." Geographical Analysis. 34(4):330-349.

Williams, J.C., and C.S. ReVelle. 1998. "Reserve Assemblage of Critical Areas: A Zero-One Programming Approach.” European Journal of Operational Research 104(3):497-509. 
Williams, J.C., C.S. ReVelle, and S.A. Levin. 2005. "Spatial Sttributes and Reserve Design Models: A Review." Environmental Modeling \& Assessment. 10(3):163-181.

Yohe, G., J. Neumann, P. Marshall, and H. Ameden. 1996. "The Economic Cost of GreenhouseInduced Sea-Level Rise for Developed Property in the United States." Climatic Change. 32 (4):387-410.

Young., J. 2012. “Town of Phippsburg Selectmen’s Meeting Minutes.” Phippusburg, ME.

\section{Appendix A - Detailed Simulation Results}

\section{Variations in Budget Constraints}

The forward-looking model that accounts for sea level rise achieves higher benefits across various amounts of budget. As seen in Appendix Figure 1a, given a budget range between $\$ 25$ and $\$ 230$, a model that incorporates expectations of sea-level rise into the decision-making process always results in higher realized benefits. A one-tail, two-sample mean comparison test indicates the benefit of expecting sea-level rise is statistically significant at a less than 1-percent level ( $p$-value $=0.0092$ ).

The exercise also shows where the difference between the two models is greatest. It appears there may be a range of budgets where the benefit of incorporating sea-level rise expectations is greatest, around $\$ 100$ given the parameters of this model. It also shows a convergence at either end of the budget spectrum where the differences between the two models is small (see Appendix Figure 1b). The decrease of the differences between the two models at low and high budgets is to be expected; when the budget is small, only a small number of parcels can be bought, limiting the difference, and when the budget is large, most of the landscape is purchased again, limiting the differences between the selections.

\section{Variations in Severity of Sea-Level Rise}

In Scenario 3 we fix the budget, and vary the mean severity of sea-level rise. We use a budget of $\$ 150$ and model nine mean severity levels ranging from 10 percent to 90 percent, each with a range of 20 percent as indicated in Appendix Table 1. We find that both organizations have the highest benefits when mean sea-level rise is the smallest (Appendix Figure 2a), an intuitive result, and also that the advantage of the forward looking (over the myopic model) decreases as the severity of sea-level rise approaches complete (100 percent) inundation; see Appendix Figure $2 \mathrm{~b}$. A possible reason for this is that at very high levels of sealevel rise, a significant part of the landscape is inundated, accounting for climate change when planning does not result in additional benefits.

The average difference (calculated as the realized benefits for the model incorporating expectations minus the realized benefits for the model ignoring them for each simulation) is nine units (SD 5.89). A one-tail, mean 
(a)

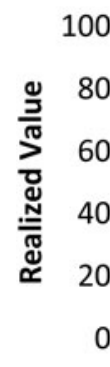

Benefits Over Varied Budgets

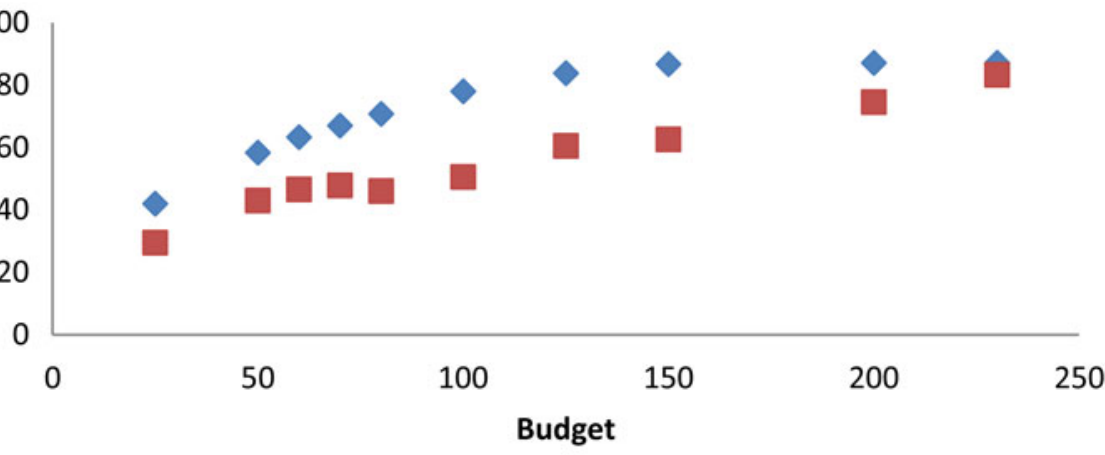

Sea Level Rise Expected $\quad$ No Expectations

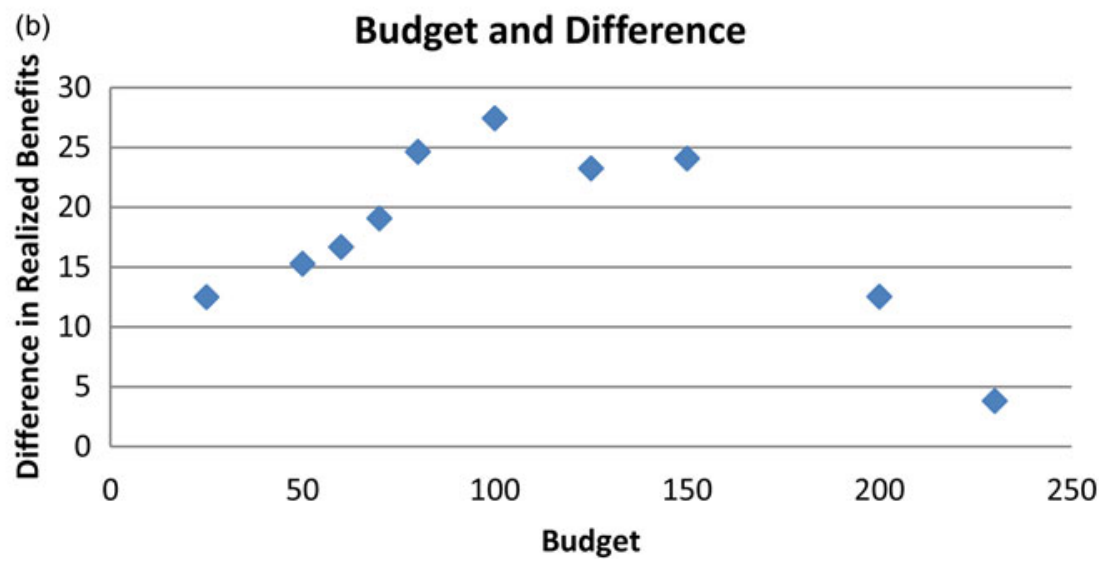

Appendix Figure 1. (a) Realized Benefits after N Years after Selecting Land, Either Expecting or Not Expecting Sea-Level Rise to Occur. (b) Differences in Realized Benefits after Selecting Land, Either Expecting or Not Expecting Sea-Level Rise to Occur, Varied across Different Budgets.

sample comparison test indicates that the additional benefits of incorporating sea-level rise are statistically significant at the 1-percent level ( $p$-value $=$ 0.0015).

\section{Variations in Risk}

In the final scenario we vary the range of the severity of sea-level rise (i.e., the risk) around a mean of 50 percent of the land being inundated. At lower ranges, and therefore lower uncertainty, both agents see lower benefits than at higher ranges of uncertainty. This may be because of where the mean level of rise was 
(a)

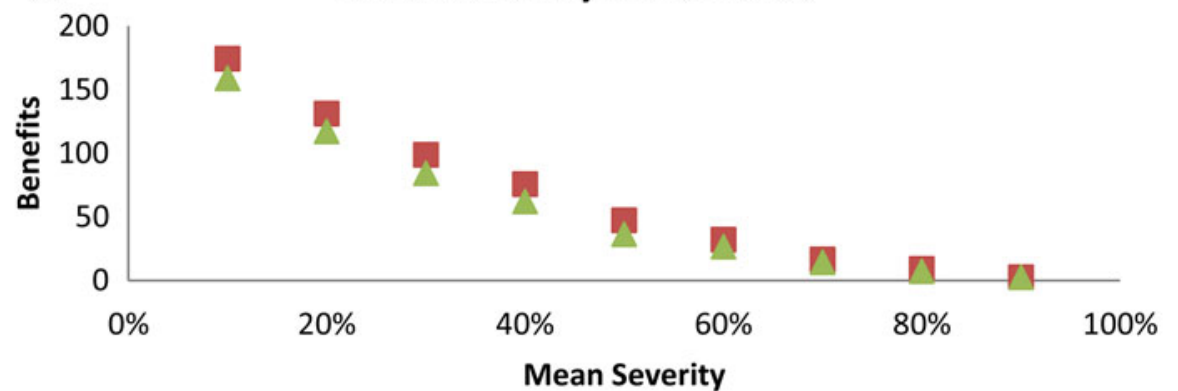

Sea-Level Rise Expected $\Delta$ No Rise Expected

(b)

Mean Severity vs. Difference in Benefits

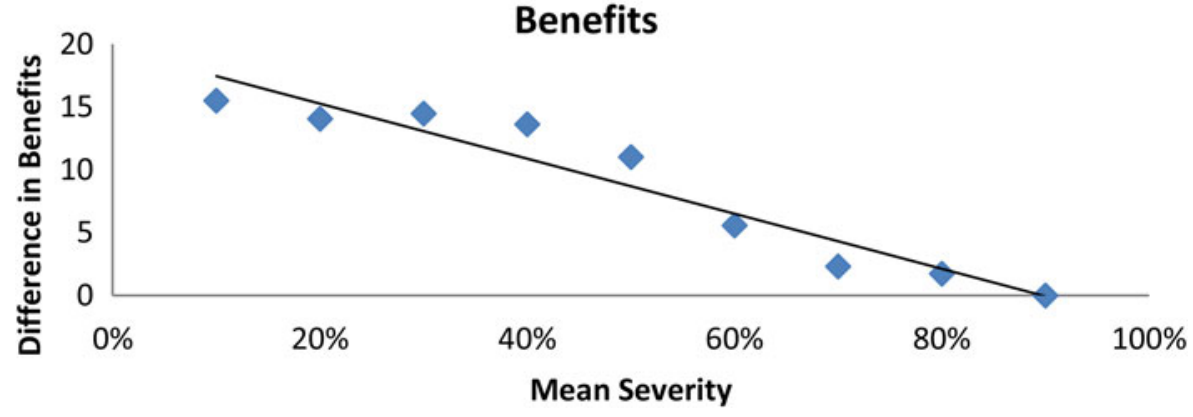

Appendix Figure 2. (a) Realized Benefits After N Years after Selecting Land, Either Expecting or Not Expecting Sea-Level Rise to Occur, Varied by the Mean Severity of Sea-Level Rise Predicted. (b) The difference in Realized Benefits after $\mathbf{N}$ Years after Selecting Land Either Expecting or Not Expecting Sea-Level Rise to Occur, Varied by the Mean Severity of Sea-Level Rise Predicted. A Linear Trend Line is Shown.

set; at lower levels of uncertainty, more parcels experience higher levels of flooding because lower severities are not possible. At higher levels of uncertainty, catastrophic levels of flooding are possible, but so is minimal flooding. See Appendix Table 2 for a summary of the results.

At all levels of uncertainty, given a mean severity of 50-percent loss, the agent who expects sea-level rise to occur has a higher level of benefits after $\mathrm{N}$ years than the agent who does not. The difference in realized benefits between the two agents increases as the range of sea-level-rise severity increases, so with more uncertainty it becomes advantageous to have incorporated the expectation of sea-level rise into your decision-making process. The average difference (calculated as the realized benefits for the model incorporating expectations minus the realized benefits for the model ignoring them for each 
Appendix Table 1. Parameter Values and Results for Scenario 3

\begin{tabular}{lccccc}
\hline $\begin{array}{l}\text { Predicted } \\
\text { Loss Range }\end{array}$ & $\begin{array}{c}\text { Mean } \\
\text { Severity }\end{array}$ & Range & $\begin{array}{c}\text { Model 1 } \\
\text { Realized } \\
\text { Benefits }\end{array}$ & $\begin{array}{c}\text { Model 2 } \\
\text { Realized } \\
\text { Benefits }\end{array}$ & $\begin{array}{c}\text { Difference in } \\
\text { Realized } \\
\text { Benefits }\end{array}$ \\
\hline $0-20$ & $10 \%$ & 20 & 174 & 159 & 15 \\
$10-30$ & $20 \%$ & 20 & 131 & 117 & 14 \\
$20-40$ & $30 \%$ & 20 & 99 & 84 & 14 \\
$30-50$ & $40 \%$ & 20 & 76 & 62 & 14 \\
$40-60$ & $50 \%$ & 20 & 47 & 36 & 11 \\
$50-70$ & $60 \%$ & 20 & 32 & 27 & 6 \\
$60-80$ & $70 \%$ & 20 & 17 & 14 & 2 \\
$70-90$ & $80 \%$ & 20 & 9 & 7 & 2 \\
$80-100$ & $90 \%$ & 20 & 3 & 3 & 0 \\
\hline
\end{tabular}

simulation) is 15 units (SD 2.64). A one-tail mean sample comparison test indicates that the additional benefits from incorporating sea-level rise are statistically significant at the 1 -percent level ( $p$-value $=0.0001)$.

\section{Appendix B - Setting up the Data}

To use assessed property value as a proxy for the purchasing price conservation organizations would be faced with, the area of potential wetlands under each sea-level-rise scenario needed to be associated with a tax-map. To do this, the Google Earth file was first converted to a shapefile using the ArcMap Conversion tool, resulting in a Wetland layer showing where current wetlands are, as well as areas of potential wetlands under the 1-foot, 2-foot, 3.3-foot, and 6-foot scenarios analyzed by the Marsh Migration Team. The ArcMap Projection tool was then used to project both the Wetland and Tax

Appendix Table 2. Parameter Values and Results for Scenario 4

\begin{tabular}{lccccc}
\hline $\begin{array}{l}\text { Predicted } \\
\text { Loss Range }\end{array}$ & $\begin{array}{l}\text { Mean } \\
\text { Severity }\end{array}$ & Range & $\begin{array}{l}\text { Sea-Level Rise } \\
\text { Expected }\end{array}$ & $\begin{array}{l}\text { No Rise } \\
\text { Expected }\end{array}$ & $\begin{array}{l}\text { Model } \\
\text { Difference }\end{array}$ \\
\hline $40-60$ & $50 \%$ & $10 \%$ & 47 & 35 & 12 \\
$30-70$ & $50 \%$ & $20 \%$ & 58 & 45 & 13 \\
$20-80$ & $50 \%$ & $30 \%$ & 62 & 45 & 16 \\
$10-90$ & $50 \%$ & $40 \%$ & 70 & 56 & 14 \\
$0-100$ & $50 \%$ & $50 \%$ & 96 & 77 & 19 \\
\hline
\end{tabular}


Map layers into NAD1983 UTM19N from their original (mismatched) projections. This projection insured both layers used the same geographical coordinates and were accurately aligned spatially.

Next, the Intersect tool in ArcMap was used to produce a new layer, including only those locations that included both a map-lot and an area of either current or potential wetlands. Unfortunately, due to the scale at which the tax maps were drawn, the two layers did not always intersect as they should have. As the island lots were purposefully drawn closer to the mainland than they should have been for printing purposes (J.C. Wilson-Hennessey, IFA, CMA, personal communication), these lots were excluded from the optimization analysis.

Having obtained the output layer including only the areas of intersection between the wetland area and tax-maps, the data included multiple rows for each map-lot, one for each separate wetland polygon with which the map-lot intersected. Excel was used to organize the data so that each row had one map-lot and one area, and each column had only areas belonging to that columns sea-level-rise scenario. This was then collapsed using Stata, resulting in a data set with a unique row for each unique map-lot, with the sum of potential wetland area under each scenario. Excel's match and index functions were then used to associate the correct assessed value for that map-lot and the map-lot type (parcel, town, conservation) as had been coded by the town's mapper. 